\title{
Bad experience repeated eleven times
}

\author{
Aamir Shahzad ${ }^{a}$ \\ aProfessor Department of Medicine, Director Academics (Clinical) National University of Medical Sciences Rawalpindi. \\ *Corresponding Author's e-mail: aamir.shahzad@numspak.edu.pk
}

Shahzad A. Bad experience repeated eleven times. Journal of University Medical \& Dental College. 2021;12(4):v-vi. https://doi. org/10.37723/jumdc.v12i4.679

COVID-19 pandemic is raging across the land. All types of funny prescriptions can be seen, contrary to scientific guidelines. It appears, all hell of quackery has broken loose. The blunderbuss approach to treat patients without logic is especially obvious in mild to moderate cases of COVID-19 which comprise about $80 \%$ of patients. Even professors of Medicine are advising and treating patients to start vitamins to 'build Immunity' (God knows what they mean actually), putting even afebrile patients on antibiotics (even multiple antibiotics. Azithromycin and Cefixime being the hot favorites). Tab Aspirin and even anticoagulants being advised in mild to moderate cases. Dexamethosone is being touted as a panacea and started on the first indication of infection. Antiviral drugs are also being administrated to patients without solid scientific indications. There are still physicians who insist the antimalarial and Ivermectin have a role not only in therapeutics but also in prophylaxis and these drugs are being prescribed to immediate household contacts of patients. All this goes against the consensus among international medical fraternity but who cares ${ }^{[1]}$.

It appears as if the doctors are either unaware of the latest guidelines or they simply don't bother as long as the show is going on. To me the second option sounds more plausible especially in case of senior academicians.

The rot starts with the way medical professionals are trained and groomed. Medicine is an evidence-based science. All diagnostic and therapeutic decisions must be based on the latest available medical guidelines. This point though emphasized in exams is unfortunately ignored in clinical practice; sometimes even by senior faculty members. This ultimately becomes a source of misinformation for young colleagues who tend to emulate their seniors.

During ward rounds a junior pointing out that a particular decision was contrary to scientific recommendations might be admonished that books were just rubbish and useless in practical life. Here experience reins. This approach is not only grossly incorrect but unbecoming of a teacher. These seniors need to understand that experience of any person, irrespective of his/her stature can't challenge the conclusions based on scientifically designed controlled trials.

Interestingly, in exams, every one regurgitates the information given in books but later on discarding everything learned so painstakingly during training. They feel, the bookish knowledge was only for the sake of a degree and now they have a license to practice according to their own wish and instinct.

May be the roots of contradiction go deeper as there appears to be something seriously wrong with the way science subjects are being taught in our schools and colleges. Science always comes second in authenticity when compared to local wisdom or theological teachings; something fickle and unreliable, something to be skeptical, which might mislead the unwary. Simple scientific concepts are scoffed and ridiculed during classes and students' study without believing them.

Theory of evolution being a prime example. To students, it gives an impression that scientific facts need to be memorized only to earn the laurels, no compulsion to believe them as hard facts and laws of nature.

How can we explain the prescriptions from highly qualified doctors containing instructions to take indigenous medicines, euphemistically called Tib-e-Nabwi (about which they have no idea), or writing holy verses for their supposed powers of spiritual cures?

Interesting the same faculty members would fail anyone mentioning these treatments in viva voce. This apparent Contradiction can only be explained on the basis of 'loss of faith' in science. 


\title{
Bad experience repeated eleven times
}

Most of the prescriptions in clinical practice contain $\mathrm{H} 2$ blockers as if there is an epidemic of peptic ulcer in Pakistan. Anxiolytics being given for years, though in teaching everyone cautions against their use for more than 2-3 weeks. Advising Vitamins is so common, even diabetic neuropathies being treated with injections of Vitamin B12. Even in tertiary care hospitals hypertensive crises being treated by IV injections of Furosemide to drop the pressures in factions of seconds. No one bothers about the sense or the possible consequences in future.

All these issues remind me of an incident. Once when we were trainees, a consultant claimed that he had eleven years of experience. When this was brought to our professor, he smilingly quipped that it was not eleven years of experience, it's just one year of bad experience, repeated eleven times.

\section{REFERENCE:}

1. Rajesh T. Gandhi, John B. Lynch, Carlos del Rio. Mild to moderate COVID-19. New England Journal of Medicine. 383; 2020:1757-1766.

\author{
Professor Dr Aamir Shahzad \\ $M B B S$ FCPS \\ Professor of Medicine, Director Academics (Clinical) \\ National University of Medical Sciences Rawalpindi. \\ Email: aamir.shahzad@numspak.edu.pk
}

